\title{
Occipital Condyle Fracture With Isolated Unilateral Hypoglossal Nerve Palsy
}

\author{
Jin Won Yoon, MD, Oh Kyung Lim, MD, Ki Deok Park, MD, Ju Kang Lee, MD
}

Department of Physical \& Rehabilitation Medicine, Gachon University School of Medicine, Incheon, Korea

Occipital condyle fractures (OCFs) with selective involvement of the hypoglossal canal are rare. OCFs usually occur after major trauma and combine multiple fractures. We describe a 38-year-old man who presented with neck pain and a tongue deviation to the right side after a traffic accident. Severe limitations were detected during active and passive range of neck motion in all directions. A physical examination revealed a normal gag reflex and normal mobility of the palate, larynx, and shoulder girdle. He had normal taste and general sensation in his tongue. However, he presented with a tongue deviation to the right side on protrusion. A videofluoroscopic swallowing study revealed piecemeal deglutition due to decreased tongue mobility but no aspiration of food. Plain $\mathrm{X}$-ray film findings were negative, but a computed tomography study with coronal reconstruction demonstrated a right OCF involving the hypoglossal canal. An electrodiagnostic study revealed evidence of right hypoglossal nerve palsy. We report a rare case of isolated hypoglossal nerve palsy caused by an OCF.

Keywords Occipital condyle fracture, Hypoglossal nerve, Multidetector computed tomography, Electrodiagnosis

\section{INTRODUCTION}

Occipital condyle fractures (OCFs) are rare and usually occur after high-energy blunt trauma and combine multiple fractures. OCF was first described at autopsy by Sir Charles Bell in 1817 [1]. Ninety-six cases were described in the literature between 1817 and 1994. The incidence rate is as high as $4 \%$ in autopsy for fatal head injuries [2]. However, OCFs very rarely occur after minor head trauma

Received April 23, 2013; Accepted September 7, 2013

Corresponding author: Ju Kang Lee

Department of Physical \& Rehabilitation Medicine, Gachon University School of Medicine, 21 Namdong-daero 774beon-gil, Namdong-gu, Incheon 405-760, Korea

Tel: +82-32-460-8427, Fax: +82-32-460-3722, E-mail: pmrdoc@gilhospital. com

(c) This is an open-access article distributed under the terms of the Creative Commons Attribution Non-Commercial License (http://creativecommons. org/licenses/by-nc/3.0) which permits unrestricted noncommercial use, distribution, and reproduction in any medium, provided the original work is properly cited.

Copyright ( 2014 by Korean Academy of Rehabilitation Medicine
[3]. Diagnosis may be delayed or difficult because plain radiographs and conventional brain computed tomography (CT) do not provide an accurate assessment of OCFs. Only one case of OCF combined with delayed hypoglossal nerve palsy due to trauma was reported in 1998 in Korea. In accordance with the Anderson and Montesano [1] classification system of OCF, it was classified as a type I OCF [4]. We report a case of a type III occipital condyle avulsion fracture with isolated hypoglossal nerve palsy due to lateral bending moment.

\section{CASE REPORT}

A 38-year-old male was involved in a side-impact motor vehicle collision in which he was the driver. He had no particular underlying diseases in the past. He lost consciousness for 10 minutes. By the time he visited the emergency department, he had a Glasgow Coma Score of E4V5M6, normal vital signs, but bleeding through the left 
ear canal. He complained of severe neck pain with limitations of active and passive range of motion in all directions. His tongue was swollen combined with lacerations in the oral cavity. Results of blood and urine tests were within normal ranges. Plane radiographic findings of the spine, hand, elbow, knee, and skull revealed no obvious fractures. Conventional axial CT of the brain and cervical spine revealed no abnormal lesions except mild central bulging disc at the C3-4 level. Physical and neurological examinations revealed a normal gag reflex and normal

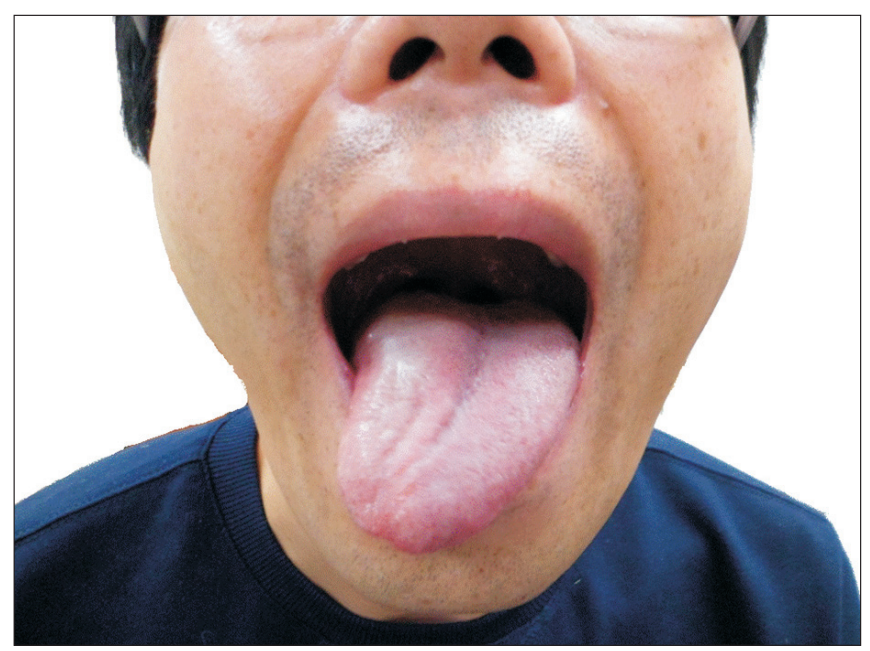

Fig. 1. Tongue deviates to the right side on protrusion, and it is atrophied on the right side. mobility of the palate, larynx, and shoulder girdle. He had normal taste and general sensation in his tongue. However, he presented with $\mathrm{s}$ tongue deviation to the right side on protrusion. The swollen tongue improved on day 10 of admission, but his tongue still deviated to the right on protrusion (Fig. 1). Thus, further imaging of the craniocervical junction was performed. A high resolution thinslice CT of the craniocervical junction demonstrated an avulsion fracture of the right occipital condyle involving the right hypoglossal canal. The stability of occipitoatlantal and atlantoaxial joint was maintained according to the criteria of Hanson's study, which suggest instability when distance of the occipitoatlantal joint is $>2 \mathrm{~mm}$ or that of the atlantoaxial joint is $>3 \mathrm{~mm}$ (Fig. 2) [5]. An electrodiagnostic study and a videofluoroscopic swallowing study (VFSS) were performed 25 days after the injury to confirm the degree of damage to cranial nerves. The blink reflex test was within the normal range. Facial nerve and accessory nerve conduction studies were performed. The peak to peak amplitude and onset latency of the compound muscle action potential of the right accessory nerve and left facial nerve were within normal ranges (Table 1). A needle electromyographic study showed abnormal spontaneous activities such as positive sharp waves and fibrillation potentials with polyphasic motor unit potentials and reduced recruitment in the right genioglossus muscle. A needle electromyographic study of the trapezius
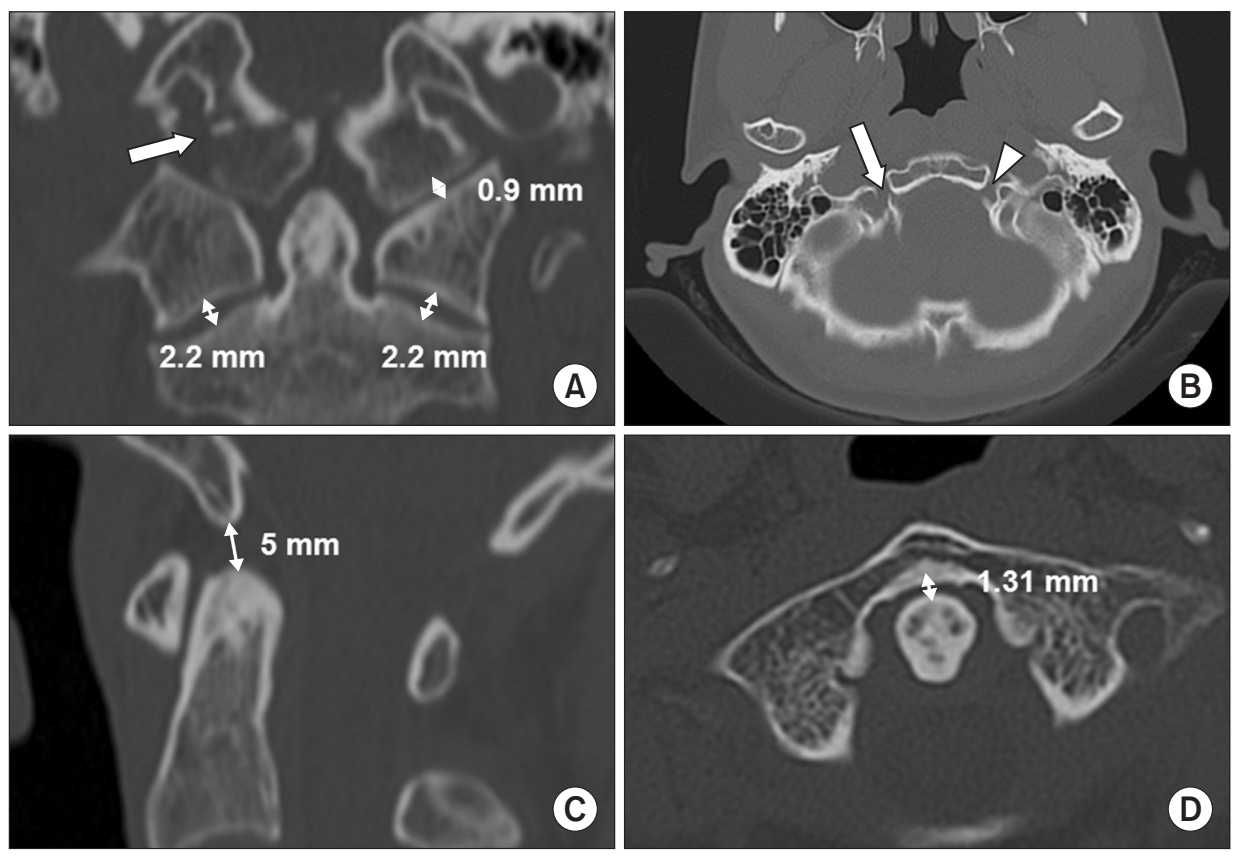

Fig. 2. (A) Computed tomography scan reveals an Anderson and Montesano type III occipital condyle fracture (arrow) and no widening of the occipitoatlantal or atlantoaxial joints. (B) The occipital condyle fracture involves the right hypoglossal canal (arrow) but the left hypoglossal canal is intact (arrowhead). Structural stability of the craniocervical joints is maintained with (C) a basiondens interval of $5 \mathrm{~mm}$ and (D) an anterior atlanto-dens interval of $1.31 \mathrm{~mm}$. 
Table 1. Nerve conduction study results

\begin{tabular}{|c|c|c|c|c|c|}
\hline \multirow{2}{*}{ Stimulation site } & \multirow{2}{*}{ Recording site } & \multicolumn{3}{|c|}{ Latency (ms) } & \multirow{2}{*}{$\begin{array}{l}\text { Amplitude } \\
\text { (mV) }\end{array}$} \\
\hline & & Onset & R1 & $\mathbf{R 2}$ & \\
\hline \multicolumn{6}{|l|}{ Nerve conduction study } \\
\hline Lt spinal accessory nerve & Upper trapezius & 2.70 & - & - & 12.1 \\
\hline Rt spinal accessory nerve & Upper trapezius & 2.90 & - & - & 12.4 \\
\hline Lt facial nerve & Left nasalis & 3.10 & - & - & 3.5 \\
\hline Rt facial nerve & Right nasalis & 2.95 & - & - & 5.5 \\
\hline \multicolumn{6}{|l|}{ Blink reflex test } \\
\hline \multirow[t]{2}{*}{ Lt supraorbital nerve } & Left orbicularis oculi & - & 12.55 & 25.40 & - \\
\hline & Right orbicularis oculi & - & & 25.50 & - \\
\hline \multirow[t]{2}{*}{ Rt supraorbital nerve } & Right orbicularis oculi & - & 11.55 & 25.75 & - \\
\hline & Left orbicularis oculi & - & & 25.15 & - \\
\hline
\end{tabular}

Table 2. Needle electromyographic findings

\begin{tabular}{llcll}
\multicolumn{1}{c}{ Muscle } & IA & Spontaneous activity & MUAPs & Recruitment pattern \\
\hline Lt tongue & Normal & - & Normal & Full \\
Rt tongue & Increased & Fibs \& PSWs $(+)$ & Polyphasic & Reduced \\
Rt SCM & Normal & - & Normal & Full \\
Rt upper trapezius & Normal & - & Normal & Full \\
\hline
\end{tabular}

SCM, sternocleidomastoid muscle; IA, insertional activity; Fibs, fibrillation potentials; PSWs, positive sharp waves; MUAPs, motor unit action potentials; Full, full recruitment pattern; Reduced, reduced recruitment pattern.

and sternocleidomastoideus muscles was normal (Table 2). The electromyographic findings confirmed an isolated incomplete right hypoglossal nerve lesion. VFSS showed retention of food in the oral cavity after swallowing and piecemeal deglutition due to decreased tongue motility in the oral phase. The pharyngeal swallowing phase was normal. Vocal cord mobility was normal on a laryngeal endoscopic examination.

A CT scan showed no structural instability of the craniocervical joints, so we applied a Philadelphia collar for 6 weeks to prohibit excess neck motion and physical therapy for pain control. The patient performed strength exercises and range of motion exercises for the oral tongue muscles. The Korean version of Neck Disability Index (NDI) was used to assess disability due to neck pain [6]. The NDI score was 50 at 1 day after the injury and it was 21 at 25 days after the injury. The NDI score had dropped to 12 at 56 days after the injury. Thus, neck pain had improved. Deviation of the tongue to the right side improved partially 8 weeks after the injury. A followup CT scan and dynamic cervical radiographs 16 weeks after the injury revealed stable craniocervical joint struc- ture (Fig. 3).

\section{DISCUSSION}

The major cause of an OCF is high-energy trauma and occasionally severe head injury is involved. [7]. An OCF associated with minor head trauma is very rare [3]. The clinical presentation of individuals with an OCF varies. Lower cranial nerve deficits are noted in one-third of patients with an OCF [2]. Some cases have delayed nerve injury 1-9 weeks after the trauma $[4,8]$. Delayed nerve injury is related to formation of osseous callus or dislocation of a bony fragment [8]. Some patients complain of only headache and neck pain. Therefore, early diagnosis of an OCF is important and continuous follow-up will benefit asymptomatic patients.

In 1988, Anderson and Montesano [1] proposed a classification system and divided OCFs into three types depending on their morphology and mechanism of injury. Type I OCFs are impaction-type fractures resulting from axial loading of the skull onto the atlas. Type II OCFs are more extensive basioccipital fractures caused by a direct 

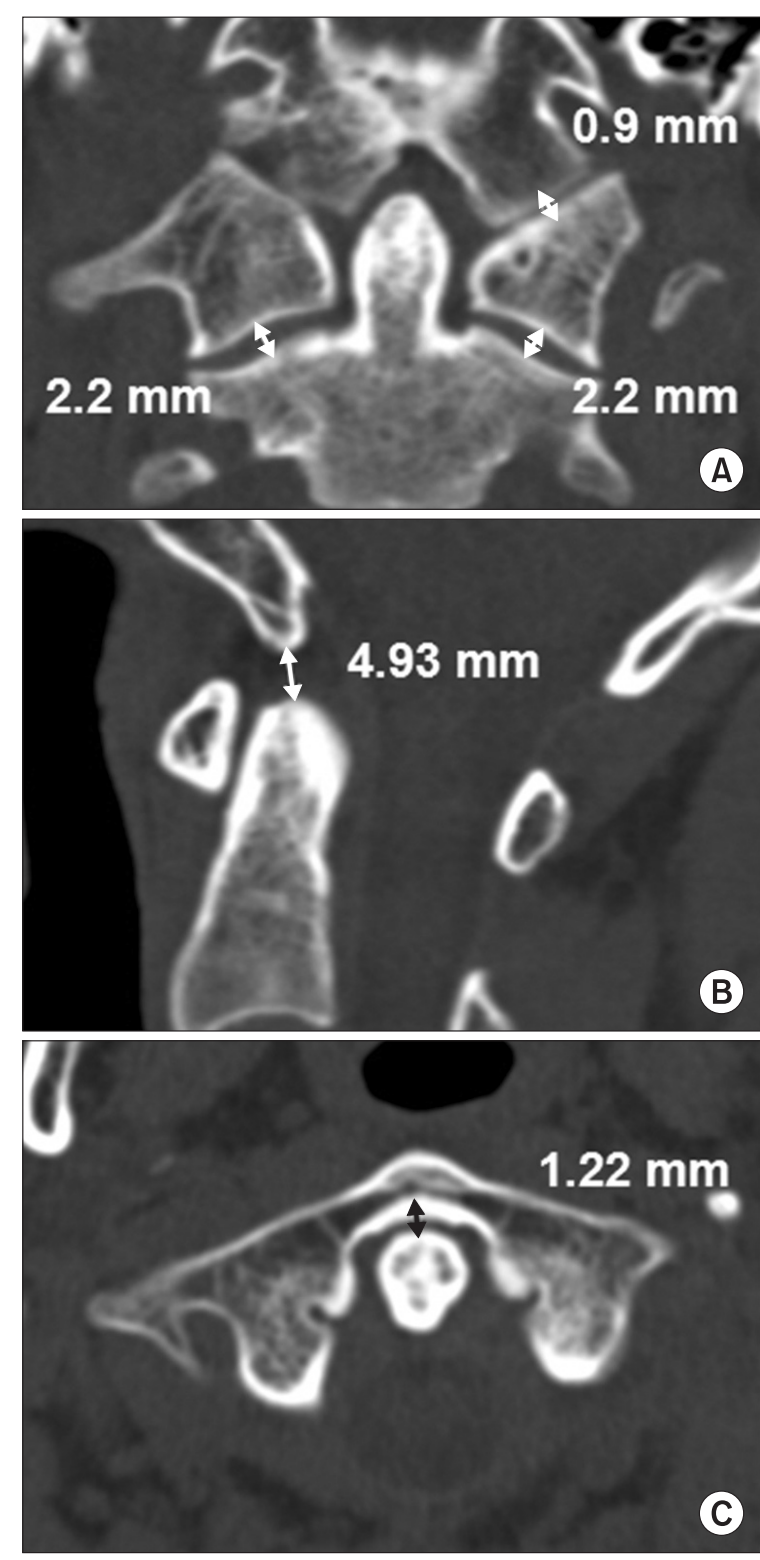
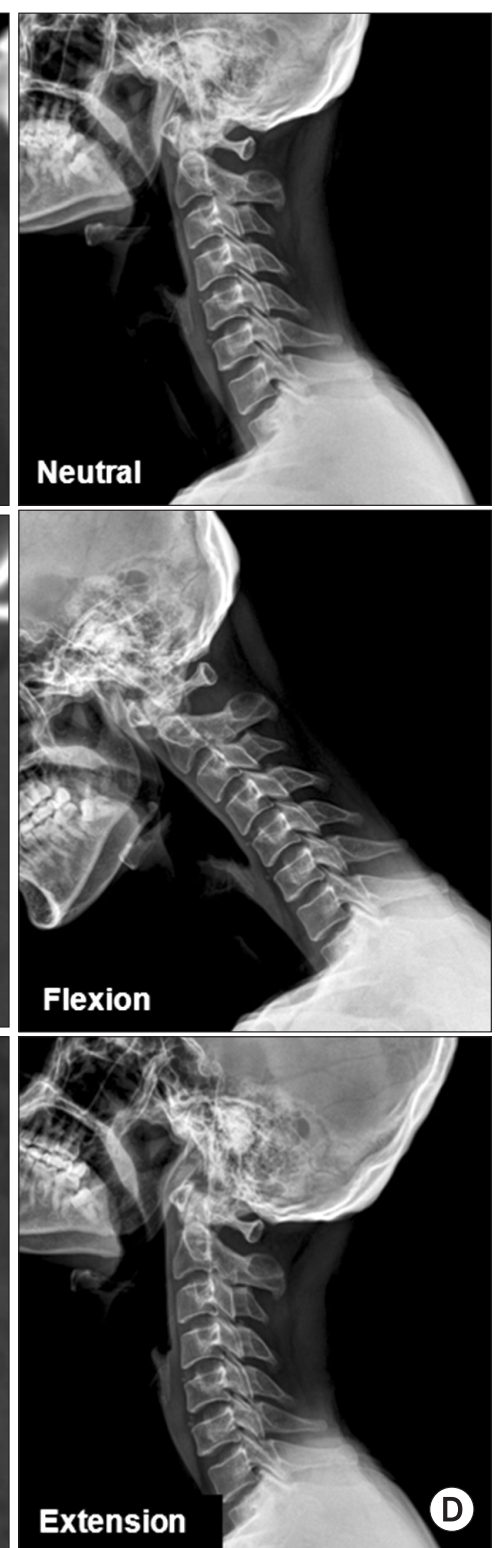

Fig. 3. Follow-up computed tomography (CT) scan and plain $\mathrm{X}$-ray performed 16 weeks after the motor vehicle crash. (A) The CT scan reveals structural stability of craniocervical joints with no widening of the occipitoatlantal or atlantoaxial joints. (B) Basiondens interval of $4.93 \mathrm{~mm}$ and (C) anterior atlanto-dens interval of $1.22 \mathrm{~mm}$. (D) Lateral view cervical radiograph shows structural stability of the craniocervical joints. blow to the skull. Type III OCFs are avulsion fractures due to a rotatory force combined with a lateral bending force. Tuli et al. [2] proposed a new classification system for managing OCFs in 1997 based on fragment displacement and stability of the atlanto-occipital and atlantoaxial joints. They divided OCFs into three types. A type 1 OCF has no fragment displacement. Type 2 OCFs have fragment displacement and are subdivided into type 2a OCFs and type $2 \mathrm{~b}$ OCFs. However, the Anderson and Montesano classification is only based on six cases, and the Tuli classification as developed based on three cases. Thus, treatment for OCFs is difficult to generalize and apply using these classification systems.
Conservative management is standard treatment for stable patients with an OCF. The treatment of choice is immobilization with a hard collar for 1-3 months. $\mathrm{Pa}$ tients with an unstable OCF are treated with a halo-vest to immobilize the joints [4]. Patients who have craniocervical malalignment or neural element compression due to an OCF are treated by occipitocervical fusion for stabilization [9]. However, treatment of OCFs remains controversial because of the limited number of cases and prospective studies.

Maserati et al. [9] performed a retrospective study of 24,745 trauma patients admitted to a single level I trauma center (UPMC Presbyterian Hospital) between March 
2002 and April 2008. They identified 100 patients with 106 OCFs during the 6-year period. They recommend that craniocervical junction (CCJ) misalignment and neural element compression were indications for surgery. In their study, no neural element compression was detected. Only two patients underwent occipitocervical fusion because of an OCF associated with craniocervical misalignment. Patients who were prescribed a rigid cervical orthosis had no craniocervical instability on dynamic radiographs or craniocervical misalignment on static radiographs or CT scans in follow-up studies. Therefore, in the absence of CCJ misalignment or neural element compression, they recommends treating OCFs using a rigid cervical orthosis for 6 weeks.

Mueller et al. [10] performed a prospective study of 2,616 trauma patients admitted to a single level I trauma center (Regensburg University Hospital) between January 2005 and December 2009. They identified 31 patients with 35 OCFs and evaluated quality of life 1 year after trauma. Three patients had an atlanto-occipital dislocation (AOD). Two of the three patients died, and the other patient underwent occipitocervical fusion. The patients without AOD received conservative management using a cervical collar (hard or rigid collar) for 6 weeks. The patients maintained structural stability of craniocervical joints at the 1 year follow-up. They concluded that craniocervical stability is important regardless of the type of fracture.

In our case, initial plane radiography and conventional axial CT revealed no abnormal findings. We proceeded with further evaluation to find the cause of the tongue deviation to the right side. A high resolution thin slice CT of the CCJ demonstrated a right type III OCF without an unstable CCJ involved in the hypoglossal canal. We electrodiagnostically confirmed isolated incomplete right hypoglossal nerve palsy. We treated the patient conservatively with a Philadelphia collar for 6 weeks to limit mobility of the neck.

In summary, early detection of OCFs and an evaluation of structural stability of CCJ is important $[7,9,10]$. As in our case, OCFs are typically not visible on plain radiographs of the skull and cervical spine or conventional brain CT. Continuous neck pain or neurological symptoms caused by lower cranial nerve injury can be clinical clues of OCFs. A thorough radiographic evaluation of the
CCJ, such as thin-slice CT with sagittal and coronal reconstruction should be considered for such cases.

\section{CONFLICT OF INTEREST}

No potential conflict of interest relevant to this article was reported.

\section{REFERENCES}

1. Anderson PA, Montesano PX. Morphology and treatment of occipital condyle fractures. Spine (Phila $\mathrm{Pa}$ 1976) 1988;13:731-6.

2. Tuli S, Tator CH, Fehlings MG, Mackay M. Occipital condyle fractures. Neurosurgery 1997;41:368-77.

3. Kaushik V, Kelly G, Richards SD. Saeed SR. Isolated unilateral hypoglossal nerve palsy after minor head trauma. Clin Neurol Neurosurg 2002;105:42-7.

4. Choi HK, Chung BS, Shin MS. Delayed hypoglossal nerve palsy following fracture of the occipital condyle. J Korean Neurosurg Soc 1998;27:403-6.

5. Hanson JA, Deliganis AV, Baxter AB, Cohen WA, Linnau KF, Wilson AJ, et al. Radiologic and clinical spectrum of occipital condyle fractures: retrospective review of 107 consecutive fractures in 95 patients. AJR Am J Roentgenol 2002;178:1261-8.

6. Song KJ, Choi BW, Kim SJ, Yoon SJ. Cross-cultural adaptation and validation of the Korean version of the Neck Disability Index. J Korean Orthop Assoc 2009;44:350-9.

7. Maddox JJ, Rodriguez-Feo JA 3rd, Maddox GE, Gullung G, McGwin G, Theiss SM. Nonoperative treatment of occipital condyle fractures: an outcomes review of 32 fractures. Spine (Phila Pa 1976) 2012;37:E964-8.

8. Caroli E, Rocchi G, Orlando ER, Delfini R. Occipital condyle fractures: report of five cases and literature review. Eur Spine J 2005;14:487-92.

9. Maserati MB, Stephens B, Zohny Z, Lee JY, Kanter AS, Spiro RM, et al. Occipital condyle fractures: clinical decision rule and surgical management. J Neurosurg Spine 2009;11:388-95.

10. Mueller FJ, Fuechtmeier B, Kinner B, Rosskopf M, Neumann C, Nerlich M, et al. Occipital condyle fractures: prospective follow-up of 31 cases within 5 years at a level 1 trauma centre. Eur Spine J 2012;21:289-94. 